\title{
La Mediación Independiente
}

\author{
Juan Carlos Ariznga González
}

\begin{abstract}
Sumario
1. Introducción. 2. La Mediación en el Ecuador. 3. Fin de la Nueva Mediación Independiente.
\end{abstract}

\section{INTRODUCCIÓN}

Una posibilidad poco explorada en el Ecuador; la verdad es que los sistemas alternativos de solución de conflictos, entre los que se encuentra la mediación, son poco conocidos en el país y rara vez aplicados en las relaciones comerciales.

Permanentemente las instituciones que llevan adelante este magnífico medio para solucionar diferendos, están realizando cursos, seminarios y charlas; buscando que la gente común conozca de esta posibilidad y que los empresarios y comerciantes entiendan los beneficios de este sistema. Continúan capacitando a mediadores, secretarios arbitrales y árbitros, para que presten un servicio calificado, con conocimientos y técnicas probadas, para lograr resultados altamente profesionales.

\section{LA MEdiaCión EN El ECUAdor}

No es menos cierto que la penetración de los sistemas alternativos de solución de conflictos, apenas ha logrado un mínimo conocimiento en la población del Ecuador, a pesar de que en las 
facultades de derecho de todas las universidades ecuatorianas se dicta esta asignatura y este debería ser un difuminador efectivo de este procedimiento.

En este orden de cosas, en estos últimos meses, se ha dictado un seminario, dirigido a estudiantes, público en general, jueces y abogados; sobre las bondades que tiene y que pudieran replicarse en Ecuador, de la mediación independiente. Miembros de la Fundación americana, JAMS; nos han contado de manera clara y contundente sobre como actúa este procedimiento; que es lo que están haciendo en los Estados Unidos de América y como llevarlo a cabo en Ecuador.

Nuestra legislación, a través de la Ley de arbitraje y mediación y su Reglamento, claramente se pronuncian sobre esta posibilidad, expresándose de la siguiente manera:

Ley de Arbitraje y Mediación

Art. 43.- La mediación es un procedimiento de solución de conflictos por el cual las partes, asistidas por un tercero neutral llamado medindor, procuran un acuerdo voluntario, que verse sobre materia transigible, de carácter extrajudicial y definitivo, que ponga fin al conflicto.

Art. 44.- La mediación podrá solicitarse a los centros de mediación o a mediadores independientes debidamente autorizados.

Podrain someterse al procedimiento de mediación que establece la presente Ley, sin restricción alguna, las personas naturales o jurídicas, puiblicas o privadas, legalmente capaces para transigir.

El Estado o las instituciones del sector público podrán someterse a mediación, a través del personero facultado para contratar a nombre de la institución respectiva. La facultad del personero podrá delegarse mediante poder.

En consecuencia, es perfectamente viable que practiquemos la mediación, fuera de los centros de Mediación y Arbitraje. 
Este concepto no pretende echar abajo la actividad de los Centros de Mediación y Arbitraje, sino por el contrario convertirse en aliados de los Centros en la promoción y aplicación de la Ley de Arbitraje y Mediación.

¿Cómo operaría este mecanismo en el Ecuador bajo nuestra legislación? La respuesta es, como manda la Ley, obteniendo los mediadores una autorización para que determinada persona pueda ejercer como Mediador Independiente, autorizado por determinado Centro de Mediación y Arbitraje.

Toda la logística que implica llevar adelante una mediación, la absorberá el mediador independiente, asumiendo mucho del trabajo operativo que desarrollan los Centros en la actualidad.

Por ahora, el mediador desarrolla una postura bastante neutra e inflexible, frente a las partes de la mediación; según el modelo Harvaniano, el mediador no debería tomar parte en la mediación o sugerir tal o cual acción. Esto desde un punto de vista purista, significa que prácticamente el mediador se limitará a dar la palabra a uno y otro y tratar de mantener un diálogo en orden, entre las partes.

Personalmente, no comparto esta forma de llevar adelante una mediación y en mi práctica como mediador, difiero significativamente de este procedimiento. En mis mediaciones soy muy agresivo y busco siempre que las partes se mantengan en la mediación y que logren acuerdos; usando para ello las tácticas que me permite el Reglamento. Estas son usualmente en salas separadas o alternando primero una reunión con una parte y luego con otra; muchas veces evitando que las partes tengan contacto y llevando posiciones de uno a otro, hasta alcanzar el acuerdo esperado, pero interactuando y motivando, haciendo ver a las partes lo negativo de no llegar a acuerdos o lo impracticable de sus posiciones. 
La habilidad con la que se desempeñe el mediador, puede conseguir que posiciones antagónicas concluyan encontrando puntos de arreglo o variantes que allanen el camino a una solución.

En la mediación independiente, partimos del hecho de que las partes han resuelto utilizar este camino y son ellos los que designan a un mediador, no con la intención de que se convierta en un perito dirimente, sino que los conduzca hacia un acuerdo práctico y ejecutable para las partes.

El procedimiento varía un poco de la forma tradicional, en el sentido de que el mediador designado por las partes, entrará en contacto con el proceso, antes de la primera reunión, es decir se inteligenciará de los elementos y contenidos de la disputa y posterior a ello podrá reunirse conjunta o individualmente con las partes.

El mediador, estudiará el caso, buscará todo el conocimiento posible sobre el tema de diferendo y con estos elementos, trabajará una fórmula de acuerdo con las partes.

A diferencia de la mediación tradicional o administrada, el mediador utilizará a los abogados de las partes para que sean ellos quienes aconsejen al cliente, la bondad de llegar a un acuerdo. La función de los abogados es primordial porque les permitirá a las partes encontrar todos los elementos de riesgo en sus posiciones y las ventajas de alcanzar un acuerdo.

Puede en este procedimiento adelantarse la entrega de pruebas de manera que las partes jueguen con las cartas echadas sobre la mesa; de esta manera arribar a un acuerdo se vuelve una tarea más gratificante pues no se trata de establecer la verdad del uno frente a la verdad del otro, sino lograr un acuerdo basado en la información de las partes.

Esto logra acuerdos duraderos y ejecutables, pues no existe peor acuerdo que aquel que no se logra cumplir o que trae nuevos problemas en su ejecución. 
¿Por qué es importante para las partes este procedimiento? Es importante y los empresarios lo buscan, porque les ofrece la posibilidad de encontrar a la persona que consideren mejor para servir a sus intereses y en consecuencia buscarán al mediador que más éxito presente, a fin de que intente alcanzar un acuerdo con la contraparte beligerante.

El mediador más preparado y que mejores ejecutorias puede exhibir a sus clientes, será el mediador más demandado y como toda mercadería, ante una oferta escasa la demanda ofrecerá mejor remuneración a quien mejor se desempeñe; siendo este un gran atractivo para quien decida dedicar su esfuerzo a este tipo de actividad.

Actualmente la mediación es llevada a cabo por los Centros de Mediación y sus mediadores son profesionales de buena voluntad que en su mayoría no la ejecutan como un medio de vida, sino como una forma de servicio comunitario, que brinda prestigio y muchas satisfacciones personales y ocasionalmente un salario adecuado.

\section{Fin dE LA NUEVA MEdiación INDEPENDIENTE}

Lo que busca la nueva mediación independiente, es que esto se convierta en una fuente de ingresos permanentes para los mediadores, fuente de ingresos que les permita una vida digna en función de su desarrollo profesional. Esto significa que el profesional estará destinando las ocho horas de trabajo diario a esta actividad, es decir todo su tiempo efectivo y las horas extras que demande el proceso, pero se verá debidamente remunerado por las partes, sin importar el resultado que se obtenga y previo a realizar el trabajo; lo cual obliga a las partes y al mediador a dar lo mejor de si en el tiempo contratado.

Los costos de mediación, no podrán ser los mismos, pero por otro lado, estos costos vistos desde la empresa, representarán de 
manera exacta el costo por hora de un profesional que destina todo su tiempo, experiencia y energía a lograr solucionar sus problemas, sin tener una relación directa con la cuantía del caso que se trate.

Con este mecanismo, las partes que se presenten a mediación, estarán muy interesadas en aprovechar al máximo el tiempo previamente pagado, para llegar a un acuerdo, sin dilatorias y buscando ser lo más eficientes posibles en el tiempo y en la búsqueda del acuerdo.

Si la mediación se lleva a cabo por un mediador independiente autorizado por un centro de Arbitraje y Mediación, el acta que suscriban las partes y cuyo acuerdo lo avala el mediador independiente, tiene fuerza de sentencia ejecutoriada, de última instancia. Por tanto su cumplimiento es obligatorio para las partes.

Esto que parece poca cosa, es de singular importancia, pues quizá la duda mayor de los usuarios es como hacer efectiva la ejecución de un acuerdo de mediación y hay que reconocer, la justicia ecuatoriana ha sabido respetar y hacer cumplir, con celeridad, los acuerdos alcanzados por las partes. Resta decir que son muy pocos los casos en los que un acuerdo de mediación no se lo cumple y se hace necesario acudir a la justicia ordinaria para lograr su cumplimiento.

¿Podremos tener este servicio en Ecuador? Mucho depende de empresarios, abogados y mediadores; que comprendamos la necesidad de un sistema como el que se explica y la eficiencia en lograr los acuerdos que se requieran. Un nuevo reto muy atractivo para quienes estamos convencidos de la efectividad de los medios alternativos de solución de conflictos. 